\title{
Highly dynamic transient colonization by Staphylococcus aureus in healthy Malaysian students
}

Staphylococcus aureus carriage is a risk factor for infection in both community and hospital settings. Three main $S$. aureus carriage patterns have been described: non-carriage, persistent carriage

(repeatedly culture-positive) and transient or intermittent carriage (may or may not carry at different time intervals). Persistent carriage in particular is associated with a higher risk for infections (Nouwen et al., 2005, 2006). Although the anterior nares are the primary colonization site for $S$. aureus, throat carriage has frequently been reported (Uemura et al., 2004; Mertz et al., 2007). In Malaysia, the prevalence of nasal carriage of $S$. aureus is within the reported range of 20-25\% (Choi et al., 2006; Neela et al., 2008). However, data on the pattern of $S$. aureus carriage and the incidence of throat colonization are still uknown.

Therefore, the aims of the current study were to determine the $S$. aureus carriage pattern of local Malaysian residents and the incidence of strain carriage in the nose and throat and to investigate the strain types carried in the nose and throat of the same subject.

A total of 324 nasal and throat swabs were collected by a trained health-care worker from 162 healthy students at the Faculty of Medicine and Health Sciences, Universiti Putra Malaysia, Serdang (Mertz et al., 2007). Among the 162 subjects sampled, 95 (58.6\%), $64(3.5 \%)$ and $3(1.9 \%)$ were

Malay, Chinese and Indian, respectively. $S$. aureus was isolated and identified from the nasal and throat swabs of the subjects as described by Uemura et al. (2004). The possibility of more than one strain type per sample was hereby ignored. Subjects positive for $S$. aureus in either their throat or nose were further sampled 1 month after the first sampling to determine their carriage pattern. spa typing was carried out according to Harmsen et al. (2003). All S. aureus isolates were tested for oxacillin resistance by using an oxacillin and a cefoxitin disc, in accordance with guidelines issued by the Clinical and
Laboratory Standards Institute (formerly the National Committee on Clinical Laboratory Standards). All strains were subjected to a PVL toxin gene PCR (Lina et al., 1999).

In the first investigation, among the 162 subjects screened, 51 or $31.5 \%$ (Malay, 34; Chinese, 16; Indian, 1) were colonized with S. aureus, of which $12(23.5 \%)$ and 28 $(54.9 \%)$ carried in the nose and throat, while $11(21.5 \%)$ were colonized at both anatomical sites. Twenty-two isolates from the 11 subjects colonized on both sites were subjected to spa typing; 3 carried (Table 1) the same strain in the nose and throat, while the other 8 were colonized with different strains. In the second investigation, among the 51 subjects (positive at the first investigation) screened, only $12(23.5 \%)$ were still colonized with $S$. aureus, of which 5 (41.6\%) and 7 (58.3\%) carried in the nose and the throat, while none of them were colonized at both sites. When the spa types of the strains from the 12 subjects from both investigations were compared, none of the subjects carried the same strains, indicating that the $S$. aureus carriage pattern was of a transient nature and the strains were of diverse genetic backgrounds. However, in both investigations, the sites of colonization were persistently occupied in subjects albeit with different strains. Overall, among the 162 subjects studied, $31.5 \%(n=51)$ and $68.5 \%(n=111)$ were transient carriers and non-carriers, respectively. No real persistent carriers were observed. None of the subjects were colonized with meticillin-resistant S. aureus (MRSA) or pvl-positive strains. Based on the percentage of three important ethnic groups in Malaysia, a chi-square goodness-of-fit test revealed that the prevalence of nasal carriage of meticillinsensitive $S$. aureus among different ethnic groups $(P=0.157)$ did not vary significantly.
Many studies have described the rates of nasal carriage in various populations (Kluytmans et al., 1997). Nasal carriage rates have been shown to differ among races (Findlay \& Abrahams, 1946; Noble, 1974) and also among people of different histocompatibility antigen (human leukocyte antigen) types (Kinsman et al., 1983). However, studies on the precise $S$. aureus carriage pattern are limited, despite its importance in association with infection (Nouwen et al., 2006). Here we describe the carriage pattern of $S$. aureus in healthy, young individuals in Malaysia. Overall, we found a $31.5 \%$ carriage prevalence, which is slightly higher than the rate reported in Malaysia previously (Neela et al., 2008), but within the range reported in other studies (25-35\%) (Wertheim et al., 2005). One of the main reasons for recording an elevated carriage rate could be due to the inclusion of throat carriage. Our study shows that local $S$. aureus colonization patterns are primarily transient as no identical strains were isolated during the first and second investigations that had identical spa types. The absence of MRSA supports earlier investigations that MRSA carriage is still very low outside the health-care environment in Malaysia (Choi et al., 2006; Neela et al., 2008). Although both the throat and nose are habitats for $S$. aureus, isolates from both locations in the same individual were of different clones in 8 out of 11 subjects. Our results are in accordance with the findings of Uemura et al. (2004), who reported 11 out of 16 subjects being colonized in the nose and throat by different clones of $S$. aureus.

We show that $S$. aureus carriage in Malaysians is primarily transient with diverse bacterial genotypes occurring in single individuals. This suggests that screening for S. aureus or MRSA should involve both the throat and nose. This will increase the sensitivity of testing and aid in detecting multiple strain colonization. 
Table 1. spa types of the first and second investigations

\begin{tabular}{|c|c|c|c|}
\hline \multirow[t]{2}{*}{ No. } & \multirow[t]{2}{*}{ Sample no.* } & \multicolumn{2}{|c|}{ spa type } \\
\hline & & First investigation & Second investigation \\
\hline \multirow[t]{2}{*}{1} & $1 \mathrm{~N}$ & & \\
\hline & $1 \mathrm{~T}$ & t037 & $\mathrm{t} 2360$ \\
\hline \multirow[t]{2}{*}{2} & $2 \mathrm{~N}$ & & \\
\hline & $2 \mathrm{~T}$ & $\mathrm{t} 4224$ & t008 \\
\hline \multirow[t]{2}{*}{3} & $10 \mathrm{~N}$ & & \\
\hline & $10 \mathrm{~T}$ & t008 & $\mathrm{t} 4938$ \\
\hline \multirow[t]{2}{*}{4} & $19 \mathrm{~N}$ & & \\
\hline & $19 \mathrm{~T}$ & t688 & t714 \\
\hline \multirow[t]{2}{*}{5} & $28 \mathrm{~N}$ & & \\
\hline & $28 \mathrm{~T}$ & t521 & t091 \\
\hline \multirow[t]{2}{*}{6} & $29 \mathrm{~N}$ & & \\
\hline & $29 \mathrm{~T}$ & t3864 & t359 \\
\hline \multirow[t]{2}{*}{7} & $32 \mathrm{~N}$ & & \\
\hline & $32 \mathrm{~T}$ & t60 & t267 \\
\hline \multirow[t]{2}{*}{8} & $37 \mathrm{~N}$ & $\mathrm{t} 84$ & $\mathrm{t} 2636$ \\
\hline & $37 \mathrm{~T}$ & & \\
\hline \multirow[t]{2}{*}{9} & $83 \mathrm{~N}$ & t714 & t008 \\
\hline & $83 \mathrm{~T}$ & & \\
\hline \multirow[t]{2}{*}{10} & $47 \mathrm{~N}$ & $\mathrm{t} 878$ & t359 \\
\hline & $47 \mathrm{~T}$ & t878 & \\
\hline \multirow[t]{2}{*}{11} & $49 \mathrm{~N}$ & $\mathrm{t} 189$ & $\mathrm{t} 1544$ \\
\hline & $49 \mathrm{~T}$ & $\mathrm{t} 189$ & \\
\hline \multirow[t]{2}{*}{12} & $59 \mathrm{~N}$ & t037 & $\mathrm{t} 1427$ \\
\hline & $59 \mathrm{~T}$ & t037 & \\
\hline
\end{tabular}

${ }^{\star} \mathrm{N}$, Nasal isolate; $\mathrm{T}$, throat isolate.

\section{Acknowledgements}

This research was funded by the Ministry of Science, Technology and Innovation (Mosti), Malaysia, through Escience grant 02-01-04SF0853.

\section{Neela VasanthaKumari, ${ }^{1}$ Ahmed Subeh D. Alshrari, ${ }^{1}$ Ehsanollah Ghaznavi Rad, ${ }^{1}$ Hamed Ghasemzadeh Moghaddam, ${ }^{1}$ Alex van Belkum, ${ }^{2}$ Mateg Ali Alreshidi, ${ }^{1}$ Nurfaridah Selamat ${ }^{3}$ and Mariana Nor Shamsudin ${ }^{1}$ \\ ${ }^{1}$ Department of Medical Microbiology and Parasitology, Faculty of Medicine and Health Sciences, Universiti Putra Malaysia, Serdang 43400, Selangor, Malaysia \\ ${ }^{2}$ Department of Medical Microbiology and Infectious Diseases, Erasmus}

MC, 's-Gravendijkwal 230, 3015 CE Rotterdam, The Netherlands

${ }^{3}$ Department of Community Health, Faculty of Medicine and Health Sciences, Universiti Putra Malaysia, Serdang 43400, Selangor, Malaysia

Correspondence

Neela VasanthaKumari (neela2000@hotmail.com or neela@medic.upm.edu.my)

Choi, C. S., Yin, C. S., Bakar, A. A., Sekawi, Z., Naing, N. N., Jamal, F. \& Norlijae, O. (2006). Nasal carriage of Staphylococcus aureus among healthy adults. J Microbiol Immunol Infect 39, 458-464.

Findlay, G. M. \& Abrahams, C. (1946). The incidence of staphylococci in the nose and on the skin of Africans and Europeans in West Africa. J R Army Med Corps 87, 272-274.

Harmsen, D., Claus, H., Witte, W., Rothgänger, J., Claus, H., Turnwald, D. \& Vogel, U. (2003).
Typing of methicillin-resistant Staphylococcus aureus in a university hospital setting by using novel software for spa repeat determination and database management. J Clin Microbiol 41, 54425448.

Kinsman, O. S., McKenna, R. \& Noble, W. C. (1983). Association between histocompatibility antigens (HLA) and nasal carriage of Staphylococcus aureus. J Med Microbiol 16, 215-220.

Kluytmans, J., van Belkum, A. \& Verbrugh, H. (1997). Nasal carriage of Staphylococcus aureus: epidemiology, underlying mechanisms, and associated risks. Clin Microbiol Rev 10, 505-520.

Lina, G., Piémont, Y., Godail-Gamot, F., Bes, M., Peter, M. O., Gauduchon, V., Vandenesch, F. \& Etienne, J. (1999). Involvement of PantonValentine leukocidin-producing Staphylococcus aureus in primary skin infections and pneumonia. Clin Infect Dis 29, 1128-1132.

Mertz, D., Frei, R., Jaussi, B., Tietz, A., Stebler, C., Flückiger, U. \& Widmer, A. F. (2007). Throat swabs are necessary to reliably detect carriers of Staphylococcus aureus. Clin Infect Dis 45, 475-477.

Neela, V., Ehsanollah, G. R., Zamberi, S., Van Belkum, A. \& Mariana, N. S. (2008).

Prevalence of Panton-Valentine leukocidin genes among carriage and invasive Staphylococcus aureus isolates in Malaysia. Int J Infect Dis 13, e131-e132.

Noble, W. C. (1974). Carriage of Staphylococcus aureus and beta haemolytic streptococci in relation to race. Acta Derm Venereol 54, 403-405.

Nouwen, J. L., Fieren, M. W., Snijders, S., Verbrugh, H. A. \& van Belkum, A. (2005). Persistent (not intermittent) nasal carriage of Staphylococcus aureus is the determinant of CPD-related infections. Kidney Int 67, 1084-1092.

Nouwen, J., Schouten, J., Schneebergen, P., Snijders, S., Maaskant, J., Koolen, M., van Belkum, A. \& Verbrugh, H. A. (2006). Staphylococcus aureus carriage patterns and the risk of infections associated with continuous peritoneal dialysis. J Clin Microbiol 44, 2233-2236.

Uemura, E., Kakinohana, S., Higa, N., Toma, C. \& Nakasone, N. (2004). Comparative characterization of $S$. aureus isolates from throats and noses of healthy volunteers. Jpn J Infect Dis 57, 21-24.

Wertheim, H. F., Melles, D. C., Vos, M. C., van Leeuwen, W., van Belkum, A., Verbrugh, H. A. \& Nouwen, J. L. (2005). The role of nasal carriage in Staphylococcus aureus infections. Lancet Infect Dis 5, 751-762. 